Hage, M.C.F.N.S.'; Kamikawa, L.'; Benedicto, H.G.3; Lorigados, C.A.B. ${ }^{4}$; Iwasaki, M. ${ }^{5}$; Bombonato, P.P. ${ }^{6}$; Rabbani, S.R. ; Shinohara, J.L. ${ }^{8}$; Sterman, F.A. ${ }^{9}$; Yuri, D. ${ }^{10}$

\section{3 - Utilização da ressonância magnética na avaliação anatômica do crânio normal de cão}

1-Doutoranda do Departamento de Cirurgia da Faculdade de Medicina Veterinária e Zootecnia da Universidade de São Paulo, São Paulo-SP

2-Mestranda do Departamento Anatomia da Faculdade de Medicina Veterinária e Zootecnia da Universidade de São Paulo, São Paulo-SP

3- Doutorando do Departamento Anatomia da Faculdade de Medicina Veterinária e Zootecnia da Universidade de São Paulo, São Paulo-SP

4- Mestre em Clínica pela Faculdade de Medicina Veterinária e Zootecnia da Universidade de São Paulo, São Paulo-SP

5- Professor Titular do Departamento Cirurgia da Faculdade de Medicina Veterinária e Zootecnia da Universidade de São Paulo, São Paulo-SP

6- Professor Titular do Departamento de Anatomia da Faculdade de Medicina Veterinária e Zootecnia da Universidade de São Paulo, São Paulo-SP

7- Professor Associado do Departamento de Fisica Geral do Instituto de Física da Universidade de São Paulo, São Paulo-SP

8-Engenheiro do Departamento de Física Geral do Instituto de Física da Universidade de São Paulo, São Paulo-SP 9- Professor Doutor do Departamento de Cirurgia da Faculdade de Medicina Veterinária e Zootecnia da Universidade de São Paulo, São Paulo-SP

10- Graduanda da Faculdade de Medicina Veterinária e Zootecnia da Universidade de São Paulo, São Paulo-SP

A Ressonância Magnética (RM) é uma técnica auxiliar de diagnóstico por imagem não invasiva, capaz de fornecer imagens de alta resolução e com uma grande riqueza de detalhes anatômicos em cortes sagitais, transversais e dorsais. Desde a década de 70, periodo em que se obtiveram as primeiras imagens de RM em seres vivos, até o momento atual, ocorreram grandes avanços quanto às técnicas e seqüências empregadas. A Ressonância Magnética está baseada na propriedade física exibida por núcleos de determinados elementos que quando submetidos em um conjunto de campos magnéticos e excitados por ondas de radiofrequência emitem um sinal eletromagnético em uma determinada freqüência o qual pode ser captado por uma antena e transformado em imagem através de um processo de reconstrução computadorizada. $\mathrm{O}$ átomo mais importante para a RM aplicado à medicina é o hidrogênio, devido suas propriedades magnéticas e sua abundância relativa nos tecidos vivos. Diferentes seqüências de pulso podem ser aplicadas ao sistema, ou seja, a forma que se aplica os pulsos de radiofrequência (RF) e a manipulação dos gradientes de campo magnético propiciam a aquisição de imagens com características diferentes. Embora a literatura estrangeira apresente diversos trabalhos com RM em medicina veterinária, as primeiras imagens obtidas no Brasil são recentes e ainda em fase experimental. O presente trabalho tem como objetivo precípuo correlacionar imagens obtidas através da RM do crânio de um cão normal com a anatomia descrita para a regiào. $\mathrm{O}$ animal utilizado foi um cão, fêmea, sem raça definida, de aproximadamente 2 anos de idade, mantido sob anestesia com pentobarbital. O exame foi realizado em um aparelho de RM Gyroscan S15/HP da Philips, com campo magnético de 1,5 Tesla do Departamento de Fisica Geral do Instituto de Física da Universidade de São Paulo. As imagens obtidas foram realizadas em T1. Foi possivel identificar as estruturas ósseas componentes da arquitetura da região, músculos, grandes vasos venosos e arteriais e estruturas encefálicas, além de elementos do sistema digestório e respiratório. As seguintes estruturas ósseas foram identificadas: o osso parietal, o osso temporal, o osso frontal, o osso basisfenóide, o osso etmóide, os ossos etmoturbinados, o vômer, a foice do cérebro, a bollha timpânica, o tentório ósseo do cerebelo, a protuberância do occipital, o arco zigomático e o atlas; os diferentes músculos da cabeça: o músculo occipital, o músculo temporal, o músculo longo da cabeça, o músculo genioióideo, o músculo miloióideo, o músculo masseter e o músculo pterigóideo medial; os seguintes vasos: a veia maxilar, a veia oftálmica externa dorsal e a artéria carótida interna; as seguintes estruturas encefálicas: o cérebro, o hipocampo, o cerebelo, o pedúnculo cerebelar, o aqueduto mesencefálico, os ventrículos laterais e o espaço subaracnóide; além de outras estruturas, tais como: o seio sagital dorsal, o seio frontal, o meato acústico externo, a epiglote, o palato duro, o palato mole, as pregas vocais, a cartilagem cricóide, o meato nasofaríngeo, 
o bulbo ocular, a lente, o bulbo olfatório, a glândula parótida e a medula oblonga. Diante da riqueza de detalhes anatômicos fornecidos pela RM é de extrema importância à pesquisa pelo conhecimento da normalidade, antes de partirmos para a exploração de alterações.

Fonseca Pinto, A C. B. C. ${ }^{1}$; Clemente E. A. ${ }^{2}$; Caldas, G. M. M. ${ }^{2}$; Sterman, F. A. ${ }^{3}$; Cortopassi, S. R. G.

\section{4 - Estudo dos aspectos radiográficos observados aos exames simples e contrastados de cães com compressão extra dural}

\author{
1- Professora Assistente do Departamento de Cirurgia da Faculdade de Medicina Veterinária e Zootecnia da \\ Universidade de São Paulo, São Paulo-SP \\ 2- Acadêmicos da Faculdade de Medicina Veterinária e Zootecnia da Universidade de São Paulo, São \\ Paulo-SP \\ 3- Professor Associado do Departamento de Cirurgia da Faculdade de Medicina Veterinária e Zootecnia da \\ Universidade de São Paulo, São Paulo-SP \\ 4- Professora Doutora do Departamento de Cirurgia da Faculdade de Medicina Veterinária e Zootecnia da
} Universidade de São Paulo, São Paulo-SP

A herniação discal é uma das principais afecções da medula espinal. Ela foi classificada por Hansen como: tipo I, que se caracteriza pela degeneração, ruptura do anel fibroso dorsal e extrusão do núcleo pulposo para o canal espinal e acomete mais frequentemente raças condodistróficas, e tipo II que se caracteriza pelo abaulamento do disco intervertebral sem a completa ruptura do anel fibroso (protrusão discal) e que acomete mais freqüentemente raças não condodistróficas. $\mathrm{O}$ presente trabalho teve como objetivo estudar os aspectos radiográficos observados em cães portadores de compressão extra-dural (CED) bem como as raças, idades e regiōes mais freqüentemente acometidas. Para tanto foram avaliadas radiografias simples e contrastadas de 22 cães com CED encaminhados ao serviço de diagnóstico por imagem do Hospital Veterinário da Faculdade de Medicina Veterinária e Zootecnia da Universidade de São Paulo. Os exames simples foram realizados em projeçào látero-lateral e o contrastado em projeções látero-lateral, ventro-dorsal e oblíquas quando necessário. Os aspectos radiográficos estudados ativeram-se somente aos pontos de CED diagnosticados a mielografia. Dos 22 cães estudados, $10(45 \%)$ foram classificados como portadores de extrusão (Hansen tipo I), $9(41 \%)$ apresentavam associação de extrusào e protrusão (Hansen tipo I e II), em $2(9 \%)$ não foi possível classificar a CED e em apenas 1 $(5 \%)$ foi diagnosticado somente protrusão (Hansen tipo II). No total foram observados 37 compressões extra-durais. A região mais acometida foi a tóraco-lombar (de T11 a L2) com 17 observações $(46 \%)$. Em 24 das 37 observações $(65 \%)$ foram visibilizadas calcificaçào do disco intervertebral correspondente, em 21 delas $(57 \%)$ diminuição do espaço intervertebral e em $17(46 \%)$ foi possível identificar a opacificação do forâmen intervertebral. A progressão da coluna de contraste foi interrompida em 13 cães (59\%) impossibilitando a adequada avaliaçào pela mielografia da região caudal ao ponto de obstrução, porém apenas em 2 casos $(9 \%)$ não se conseguiu avaliar e definir o tipo de $\mathrm{CED}$ a partir da associação com os achados radiográficos do exame simples. Dos 22 animais estudados, $50 \%$ eram da raça dachshund e as idades variaram de 3 a 11 anos com média de 6 anos. Os resultados obtidos demonstraram que a mielografia foi de grande importância para o diagnóstico e a avaliação da CED, e que o exame simples também conferiu informações importantes para o estabelecimento do diagnóstico. Nos casos avaliados, a região da coluna mais acometida por lesões foi a tóraco-lombar e a maior ocorrência foi a herniação discal do tipo I (extrusão). Nos pontos de CED diagnosticados a mielografia foram observadas associações de outros importantes aspectos que complementaram o diagnóstico, como: a calcificaçào do disco intervertebral, a diminuição do espaço intervertebral e a opacificação do forâmen intervertebral. Foi observado também que a raça mais acometida por esse tipo de lesão foram os dachshund e que não houve predisposição etária, mas a média de idade dos animais acometidos foi de 6 anos. 